Kamilla Biskupska

\title{
Analiza dyskursywna amerykańskich plakatów rekrutacyjnych okresu II wojny światowej
}

\section{Wstęp}

Zadaniem, jakie stawiam w tym tekście przed sobą jest przedstawienie kształtującego się dopiero, ale interesującego podejścia do materiału wizualnego, opartego na tradycji językoznawczej - analizie dyskursu (discourse analysis - dalej DA). Chcę krótko przedstawić możliwości zastosowania tego interdyscyplinarnego ujęcia obrazowości. Nośnikiem informacji, który będę analizowała, jest plakat, a materiałem badawczym amerykański plakat rekrutacyjny z okresu II wojny światowej. Przedstawię propozycję dyskursywnej analizy zebranego materiału, ze szczególnym uwzględnieniem roli barw w tym przekazie. Wybrałam kolor do rozszerzonej analizy, ponieważ mimo dynamicznego rozwoju refleksji nad wizualnością w naukach społecznych, sfera koloru pozostaje nadal nieco na uboczu zainteresowań badaczy społecznych. Jest to właściwie zrozumiałe, gdyż kolor to jednocześnie temat wdzięczny i trudny. Wdzięczny, bo jest ważnym i wszechobecnym (choć często nieuświadamianym) elementem doświadczania świata danym większości ludzi. Trudny, bo „kolor ma w sobie dużo więcej, niż okazuje oczom” (Gage 2008: 8) - wymyka się kategoriom badawczym. 


\section{Badany materiał}

Materiałem analitycznym wykorzystywanym w poniższych analizach są amerykańskie plakaty propagandowe z lat 1941-1943, zachęcające do wstępowania do armii oraz oddziałów służb pomocniczych w dalszej części artykułu nazywam je w skrócie plakatami rekrutacyjnymi. Analizowane plakaty pochodzą z dwóch archiwów propagandy wizualnej odnoszących się do obu wojen światowych. Bazy te dostępne są na stronach internetowych bibliotek: Northwestern University Library ${ }^{1}$ oraz The University of Minnesota Libraries i The Minneapolis Public Library $^{2}$. Ogółem jest to 66 plakatów, z których wybrałam 12 reprezentujących najczęściej występujące strategie tworzenia plakatów rekrutacyjnych dla przeprowadzenia $\mathrm{w}$ niniejszym artykule analiz.

Skoncentrowałam się na plakatach rekrutacyjnych, ponieważ uważam, że stanowią one jednolity zbiór danych pod względem celu, treści i kompozycji oraz wyróżniają się na tle dominującego w amerykańskiej propagandzie wojennej przekazu wizualnego, dotyczącego działań na froncie domowym.

\section{Analiza dyskursu a wizualność}

Analiza dyskursu jest propozycją badania rzeczywistości wizualnej, ukierunkowaną na poznawanie, w jaki sposób ludzie budują obrazy (werbalne i wizualne) świata bądź też światów społecznych, w których żyją.

Na zastosowanie kategorii dyskursu w odniesieniu do rzeczywistości pozajęzykowej wpłynęło z pewnością wzrastające zainteresowanie badaczy tym, co widzialne i poszukiwanie metod naukowego poznawania języka bądź też „języków wizualnych". Podobny był zresztą kontekst pojawienia się tego językoznawczego terminu w środowisku nauk społecznych. Analiza dyskursu jako podejście badawcze wywodzi się z badań nad językiem. W takim ujęciu dyskurs:

${ }^{1}$ http://www.library.northwestern.edu/govinfo/collections/wwii-posters [dostęp: 7.11.2009].

${ }^{2}$ http://digital.lib.umn.edu/warposters [dostęp: 7.11.2009]. 
jest formą użycia języka lub zdarzeniem komunikacyjnym. Dyskurs obejmuje całość aktu komunikacji, a zatem zarówno tekst, jak i czynniki pozawerbalne, jakie mu towarzyszą. Dyskurs jest zarówno normą jak i strategią w procesie tworzenia wypowiedzi. [...] Dyskurs należy do płaszczyzny pośredniej między systemem języka a realizacją tego systemu w konkretnych aktach czy gatunkach mowy, a umiejętność operowania formami dyskursywnymi należy do kompetencji komunikacyjnej użytkowników języka (Wyrwas, Sujkowska-Sobisz 2005: 33-34).

Współcześnie dyskurs wkroczył na teren nauk społecznych i przestał funkcjonować jedynie w odniesieniu do systemu językowego (saussurowskiego parole). Badacze społeczni zainteresowani dyskursem zorientowani są przede wszystkim na działania społeczne dokonujące się w języ$\mathrm{ku}$, traktowanym jako praktyka społeczna (Fairglough 1995). Obecnie wśród teoretyków dyskursu przeważa przekonanie, że jest on jednocześnie konstruujący i konstruowany przez rzeczywistość społeczną (np. Potter 1998). Z jednej strony, ludzie budują światy, w których żyja, z „zastanych", funkcjonujących już w języku opisów, wyjaśnień i kategorii, z drugiej zaś strony stale trwa renegocjowanie tychże opisów i wyjaśnień przez nieustanną zmianę doboru wyrażeń, metafor i innych dyskursywnych „narzędzi” tworzenia rzeczywistości (Potter, Wetherell, Gill, Edwards 1990: 208).

Można wskazać kilka kategorii współcześnie wypracowanych w ramach tradycyjnej DA, które umożliwiły naturalne rozszerzenie podejścia dyskursywnego o przestrzeń wizualną.

\section{Znak}

Pierwszą ważną kategorią wiążącą analizę dyskursu z przekazem wizualnym jest znak. Pojęcie to, wprowadzające do refleksji naukowej konwencjonalność związku między słowem (tym, co znaczące) a idea, którą miało przedstawiać (tym, co znaczone), zaproponowane zostało przez Ferdinanda de Saussure'a. Jednak z perspektywy rozwoju badań nad wizualnością kluczowe są rozstrzygnięcia autorstwa Charlesa Peirce'a, a mianowicie kategorie ikony, indeksu oraz symboli (Rose 2007). Te kategorie bez większych przekształceń przeniesiono na płaszczyznę rozważań nad obrazowością (Schirato, Webb 2007; Piekot 2006). Tak ujmowane znaki (zarówno werbalne, jak i wizualne) stanowią również podstawę innego ważnego pojęcia - tekstu. 


\section{Tekst}

Analiza dyskursu pierwotnie zajmowała się tekstami mówionymi i pisanymi, pochodzącymi z naturalnych sytuacji życia codziennego, np. przekazy komunikowania masowego, rozmowy formalne i nieformalne, zapiski, dokumenty różnego rodzaju. Już wtedy pojęcie tekstu było traktowane przez analityków dyskursu szeroko: „teksty mogą przyjmować wszystkie kształty i rozmiary; mogą korespondować z każdą lingwistyczną jednostką: listem, dźwiękiem, słowem, zdaniem, kombinacją zdań" (Widdowson 2004: 8). Obecnie jednak najważniejszą cechą tekstu nie jest jego językowy wymiar, lecz możliwość rozpatrywania go jako pewnej całości złożonej z rozpoznawalnych kulturowo znaków (Schirato, Webb 2007).

\section{Relacje władzy}

Innym ważnym powiązaniem między dyskursem językowym i wizualnym jest ujęcie dyskursu - jako relacji władzy - zainspirowane myślą Michela Foucaulta (1993). Dyskursywnie konstruowana rzeczywistość ma charakter selektywny - składa się z elementów (wartości, przekonań, wyobrażeń), których dobór zdeterminowany jest przyjmowaną dominująca, często zinstytucjonalizowaną wizją świata społecznego, przejawiającą się zarówno w języku, jak i w powszechnie akceptowanych sposobach obrazowania rzeczywistości. W ten sposób narzucony, odzwierciedlający sposób widzenia świata „wygranych”, dyskurs określa, co jest widzialne i niewidoczne w otaczającym świecie. Innymi słowy:

O wizualności można również myśleć jako o rodzaju dyskursu. Określony, szczególny sposób wizualizowania sprawia, że pewne rzeczy są widzialne, dostrzegane w pewien szczególny sposób a inne niewidoczne (Rose 2007: 143, podkreślenia moje - K. B.; zob. Sturken, Cartwright 2001).

Analizując dowolny przekaz wizualny, np. środków masowego przekazu (reklamy proszków do prania, programy informacyjne i sportowe, podręczniki do nauki historii, biologii itd.), można jednocześnie prześledzić, z jakich elementów składa się rzeczywistość społeczna budowana $\mathrm{w}$ tym przekazie oraz spróbować odpowiedzieć na pytanie, czego w proponowanej wersji świata nie ma. 


\section{Jak badać przekaz wizualny $w$ ramach analizy dyskursu?}

Ewa Rewers, definiując pojęcie dyskursu (w odniesieniu do systemu językowego), stwierdziła: „dyskurs jest tym poziomem wypowiedzi, który jak dwustronne lustro odbija w swoich przestrzeniach niższe poziomy organizacji języka z jednej strony, a organizację społeczeństwa z drugiej" (Rewers 1995: 43). Takie dwupłaszczyznowe rozumienie dyskursu ma odniesienie do dwóch poziomów analizy stosowanych $\mathrm{w}$ ramach DA poziomu formalnego - analizy gramatycznej czy syntaktycznej oraz poziomu kontekstu - społecznego i kulturowego zanurzenia/ uwikłania danego dyskursu. To ujęcie dyskursu można bez trudu przenieść na poziom rozważań o obrazie - on również z jednej strony zawiera całą strukturę kompozycyjna, linie, osoby, kolory, sposoby przedstawiania postaci, z drugiej kulturowy kontekst, założenia odnoszące się do rzeczywistości.

Takiemu zdefiniowaniu dyskursu odpowiada jedna $\mathrm{z}$ perspektyw ujęcia obrazu zaproponowana przez Gilian Rose. Porządkuje ona metodologiczne nastawienie badaczy, przedstawiając trzy możliwe sposoby podejścia do badanego obrazu. Każde z nich akcentuje inne elementy powstawania, funkcjonowania elementów wizualnych, wymaga różnych narzędzi oraz odpowiada na różne pytania badawcze. Dwa z tych podejść do obrazów/obiektów scharakteryzuję jedynie pokrótce, ponieważ nie są one przedmiotem moich zasadniczych rozważań. Pierwsza możliwość to perspektywa nadawcy, określana przez Rose mianem "strona produkcji” (site of production). W tym ujęciu badacz powinien zwrócić uwagę na wąski i szeroki kontekst powstania, wykorzystaną technologię, gatunek (miejsce publikacji). Kolejna możliwość to koncentracja na perspektywie odbiorcy czy też "stronie publiczności” (site of audiencing). Pewne elementy - jak technologia czy kontekst odbioru (multipleks, mieszkanie, galeria, prasa codzienna, prasa tabloidalna, serwis plotkarski) są tu wyznaczone analogicznie do ujęcia z powyżej opisanego punktu widzenia nadawcy.

W niniejszym szkicu koncentruję się na "stronie obrazu" (site of the image). To ujęcie najbliższe jest założeniom o podstawowej jednostce analizy dyskursywnej, jaką jest tekst. Podstawą tego podejścia do materiału badanego jest omawiana przeze mnie $\mathrm{w}$ dalszej części analiza formalna kompozycja, zastosowane kolory, ich walor, postaci przedstawiane, sposób ich ukazania itp. W perspektywie badawczej skoncentrowanej na stronie obrazu podejmowane są również próby odpowiedzi na pytanie o perswazyjność, społeczny efekt danego przekazu wizualnego - jego retoryczną wymowę (Rose 2007). 
Należy również zwrócić uwagę, że w przypadku materiału badawczego powstałego $\mathrm{w}$ historycznym kontekście, niedostępnym już poznaniu bezpośredniemu przez współczesnego badacza, sposoby analizy określane mianem stron nadawcy i odbiorcy pozbawione są możliwości dostępu do realnych kontekstów powstawania i odbioru analizowanych obrazów.

Plakaty wojenne z powodu swojej postulowanej perswazyjności są naturalnym materiałem badawczym dla analityka dyskursu: ich zadaniem było wyjaśnianie rzeczywistości - miały być medium "tłumaczącym działanie, sytuację, przebieg zdarzeń" (Bergström 2009: 125), ale, co być może ważniejsze, miały również za zadanie kierować uwagę odbiorców na pewne jedynie aspekty obrazowanej rzeczywistości - przede wszystkim bazując na odpowiednim przedstawianiu elementów przekazu, które za klasyczną retoryką można określić jako odpowiedzi na następujące pytania: kto? co? gdzie? za pomocą czego? dlaczego? w jaki sposób? kiedy? (Lewiński 2008: 77).

Tę klasyczną typologię można przenieść do rozważań nad wizualnością za pomocą narzędzi wypracowanych przez historię sztuki i filmoznawstwo - umożliwiających analizę formalną badanego przekazu wizualnego. Pierwszy krok tejże analizy to odpowiedź na pytanie o kolor, linię, płaszczyznę, skalę - innymi słowy omówienie kompozycji przekazu wizualnego. Te elementy wpisują się $\mathrm{w}$ porządek formalny plakatu zdeterminowany tym, co odbiorca widzi. Dopełnieniem tego poziomu jest to, jak odbiorca widzi. Na tym z kolei poziomie analizy kluczowe są elementy gramatyki języka wizualnego, w którym dany obraz został zapisany. Przykładowo, co/kto dominuje $\mathrm{w}$ przestrzeni przekazu; czy przedstawiona postać patrzy wprost na widza; jaki rodzaj ujęć zastosowano: czy jest to plan ogólny (cała sylwetka), czy ważne są elementy tła, czy jest to półzbliżenie (ciało pokazane od pasa lub splotu pacierzowego w górę), czy pełne zbliżenie (prezentowana jest jedynie twarz). Istotny może być również kąt ujęcia: czy postać przedstawiona jest z perspektywy ptasiej, tzn. powyżej linii jej oczu, czy z perspektywy żabiej - poniżej linii jej oczu (Mascelli 2008). W dalszej części tekstu będę odwoływała się do obu wspomnianych strategii opisywania kompozycji plakatu.

Kolejnym, obok analizy formalnej, narzędziem badawczym jest analiza kontekstualna - odnosząca się do bardzo ważnego dla analityka dyskursu kontekstu kulturowego (D'Alleva 2006). Na tym poziomie analiz badaczowi społecznemu $\mathrm{w}$ sukurs przychodzą językoznawcze 
prace badawcze - semantyka obrazów wizualnych i werbalnych opiera się na tych samych zasadach kodowania - w obu przypadkach punktem wyjściowym jest wspominana już kategoria znaku³. W swoich rozważaniach korzystam $\mathrm{z}$ badań nad semantyką barw $\mathrm{w}$ języku oraz ich miejscem w językowym obrazie świata ${ }^{4}$ (Tokarski 1995; Nowakowska 2008).

Jednak podjęty temat wymaga poszerzenia wiedzy nie tylko $\mathrm{w}$ odniesieniu do warstwy semantycznej, ale i ogólnej - ważne jest jak najlepsze poznanie kontekstu kulturowego istnienia i funkcjonowania danego obrazu. Przykładowo, przydatne w trakcie prowadzenia badań nad kolorem są również osiągnięcia teorii komunikacji wizualnej. W niniejszym rozdziale będę odwoływała się do typologii zaprezentowanej przez Bo Bergströma (Bergström 2009: 203-205). Badacz ten, na podstawie Systemu Kolorów Naturalnych (NCS) ${ }^{5}$ sporządził typologię relacji między kolorami, które wyznaczają odbiór barw zależnie od ich „otoczenia” kolorystycznego. Pierwszą relację autor określa mianem kolorów, które szepczą. Są to barwy znajdujące się obok siebie na kole kolorów NCS: np. żółty i czerwony oraz zielony i niebieski. Według autora są to najbardziej harmonijne połączenia kolorystyczne. Kolejną kategorią wskazaną przez szwedzkiego badacza są kolory, które mówia - nadal pochodzące z sąsiadujących ze sobą cząstek koła, ale wykazujące większą kontrastowość i mniej cech wspólnych - są to np. czerwony i niebieski. Ostatnią kategorią wskazaną przez Bergströma są kolory, które krzycza - tworzą one ze-

${ }^{3}$ Tę zbieżność podkreślają przedstawiciele różnych dyscyplin naukowych: „Informacje werbalne i obrazowe są przechowywane w pamięci za pomocą jednego, wspólnego im rodzaju kodu, niewerbalnego i abstrakcyjnego (Chlewiński 1999: 117), "przekazy werbalne i niewerbalne można badać w sposób analogiczny" (Piekot 2006: 112).

${ }^{4}$ Językowy obraz świata to „zawarta w języku interpretacja rzeczywistości, którą można ująć w postać zespołu sądów o świecie. Mogą to być sądy utrwalone w samym języku, w jego formach gramatycznych, słownictwie, kliszowanych tekstach, np. przysłowia bądź to przez formy i teksty języka implikowane (Bartmiński 1990: 110).

${ }^{5}$ System Kolorów Naturalnych (Natural Color System) opierający się na badaniach postrzegania kolorów przez ludzkie oko powstał w Skandynawskim Instytucie Koloru. Według NCS postrzegamy przede wszystkim barwy: żółta, czerwoną, niebieska, zielona, białą i czarną. Cztery pierwsze to barwy chromatyczne, dwie następne to barwy achromatyczne - niemające dominanty barwnej (nie są nasycone domieszką żadnego koloru). System NCS opisuje poszczególne barwy ich stopniem nasycenia sześcioma opisanymi barwami (Bergström 2009: 203-205). Co ciekawe, ta typologia kolorów podstawowych i naturalnych wypełniających ikonosferę, zauważona została już przez szesnastowiecznych chemików i lekarzy (Gage 2008: 35). 
stawienia najbardziej kontrastowe, oparte na kolorach z przeciwległych fragmentów koła kolorów - taką krzyczaca parą są np. barwy niebieska i żółta oraz czerwona i zielona.

Kolor był świadomie wykorzystywanym elementem przekazu propagandowego, o funkcjach wykraczających dalece poza wartości estetyczne. Za pomocą koloru starano się $\mathrm{z}$ jednej strony przyciągnąć i utrzymać wzrok przechodniów, a z drugiej był to nośnik informacji symbolicznej w tym zdyscyplinowanym i ascetycznym kompozycyjnie medium.

\section{Plakat - medium uliczne}

Początków funkcjonowania plakatu w kulturze anglosaskiej można szukać, tak jak czyni to Dariusz Kubuj, w wieku XVI:

Luter rozpoczął w 1517 roku reformację od ogłoszenia swoich słynnych tez w formie plakatu przybitego do drzwi katedry. Plakaty były wykorzystywane od tej pory dla bodaj wszystkich wielkich ideologii i inicjatyw społecznych, zachęcały zarówno do miłości, jak i do walki, głosiły hasła, z których dzisiaj jesteśmy dumni, jak i te, o których wolelibyśmy zapomnieć (Kubuj 2006: 12).

Od tego czasu plakat - walcząc o swoje miejsce z reklamami prasowymi - stopniowo staje się ważnym elementem miejskiego krajobrazu miast Europy Zachodniej, a później Stanów Zjednoczonych ${ }^{6}$. I właśnie w Stanach Zjednoczonych propagandowy kontekst tego medium znalazł szerokie zastosowanie:

w ciągu pierwszych czterdziestu lat XX wieku w Stanach Zjednoczonych władze federalne, stanowe i miejskie zamówiły ponad 30 tysięcy wzorów plakatów, promujących ochronę przeciwpożarowa, opiekę nad kobietami w ciąży, zachowanie ciszy, czytanie książek, zwalczanie chorób wenerycznych, właściwe odżywianie i inne tematy społeczne (Kubuj 2006: 34).

${ }^{6}$ Zamiłowanie do zapełniania przestrzeni miejskiej plakatami barwnie przedstawia Kubuj: „Pod koniec siedemnastego wieku reklama plakatowa była w Londynie tak popularna, że w mieście ponoć aż było od tego ciemno. [...] dzienniki w ogóle zaczęły się rozwijać, gdy w czerwcu 1700 roku władze Londynu i Westminsteru wprowadziły zakaz plakatowania" (Kubuj 2006: 13). 
Nic dziwnego, że przy tak długiej i bogatej tradycji tworzenia plakatu zaangażowanego społecznie, nośnik ten zajął ważne miejsce w amerykańskiej propagandzie wojennej obu wojen światowych wieku $\mathrm{XX}^{7}$. Oczywiście strony walczące ze sobą w Europie również chętnie i świadomie korzystały z propagandy wizualnej - ulubionymi mediami po tej stronie Atlantyku również były plakaty i ulotki ${ }^{8}$ (Król 1999). Jak zauważa Urszula Jarecka, wyniszczające działania wojenne w Europie sprawiły, że plakat nieporównywalnie bardziej rozwinął się właśnie w Stanach Zjednoczonych - pod względem liczby projektów, jak i ich nakładu (Jarecka 2008).

Plakat - niezależnie czy o przeznaczeniu komercyjnym, czy społecznym - jest medium specyficznym i o szczególnych regułach tworzenia oraz funkcjonowania. Jedną z ważniejszych cech tego medium jest przygodność jego odbioru. W czasie wojny plakaty umieszczane były w niezobowiązującej przestrzeni publicznej - na słupie ogłoszeniowym, murze, kominie, moście, latarni, w oknie wystawowym. Dlatego musiały być zaprojektowane dla mało zainteresowanego i przypadkowego widza - człowieka przechodzącego:

Plakat jest czymś, na co zwraca się uwagę przy okazji oglądania lub czytania innych rzeczy. Kontakt jest przypadkowy, a ilustracja ma olśnić z dużej odległości i oglądana w bardzo krótkim czasie (Bernstein 2005: 72).

Wskazana właściwość plakatu - przypadkowość odbioru - wymuszała na zasadach kompozycji istotne ograniczenie - prostotę. Grafik pracujący w latach czterdziestych na zamówienie Wojennej Rady Reklamy

${ }^{7} \mathrm{O}$ świadomości urzędników państwowych co do istotnego miejsca plakatu wśród narzędzi propagandowych niech świadczy fakt, że już w dzień po japońskim ataku na Pearl Harbour - w grudniu 1941 r. - wezwano do Białego Domu Leo Burnetta (założyciela znanej agencji reklamowej) i dziennikarza Roya Larsena z magazynu „Time”, którym zakomunikowano: „Musimy dysponować środkami, które pozwolą na szybkie i efektywne informowanie Amerykanów o pewnych faktach w sposób umożliwiający solidarne zaangażowanie społeczeństwa w wysiłek wojenny" (Stafiej 2002: 52; Jarecka 2008). W konsekwencji tych spotkań w styczniu 1942 r. powstaje Advertising Council, której nazwa zostaje $\mathrm{w}$ niedługim czasie przemieniona na War Advertising Council - Wojenną Radę Reklamy.

${ }^{8} \mathrm{O}$ powszechnym, przekraczającym granice sojuszy wojennych, podkradaniu pomysłów na przekaz propagandowy pisze Urszula Jarecka (Jarecka 2008: 75). Wspomina ona na przykład o docenianiu przez Hitlera brytyjskich plakatów z okresu I wojny światowej. Niemiecki dyktator "zalecał, by nazistowski aparat propagandowy uczył się z brytyjskiej reklamy tej wojny" (Jarecka 2008: 75). 
wiedział, że plakat jako medium propagandowe - mimo koniecznych uproszczeń - powinien być czytelny i w pełni zrozumiały dla przechodnia. Pisze o tym David Bernstein (2005: 69):

Dramat zmieniono na melodramat bardziej oczywisty w odbiorze i wyrazie, oddziałujący bardziej bezpośrednio i silniej [...] zawartość tekstową ograniczono do nagłówka lub sloganu, zaś projekt graficzny do niezbędnych elementów. Celem stało się takie skondensowanie wizualnego przekazu, aby ograniczyć go do jednego celnego graficznego „kalamburu”.

Dlatego też twórcy plakatów założyli, że medium to nie może zawierać złożonego przekazu - treści wymagających zastanowienia i dłuższej refleksji:

Czas nie jest sprzymierzeńcem twórcy plakatu. Ulica to nie miejsce na snucie opowieści o skomplikowanym wątku czy kreślenie subtelnego detalu (Bernstein 2005: 68).

\section{Analiza formalna plakatu rekrutacyjnego}

Wszystkie plakaty rekrutacyjne zebrane w analizowanych przeze mnie zasobach archiwalnych zbudowane są według podobnego (uproszczonego i realistycznego) schematu kompozycyjnego. Na typowym plakacie przedstawione są postaci ludzkie - najczęściej jest to jedna osoba,

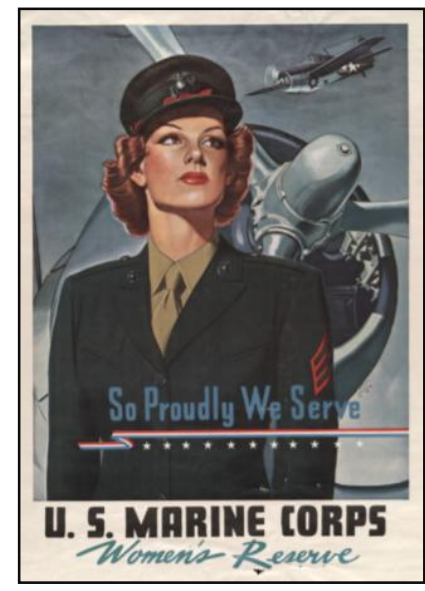

Plakat 1

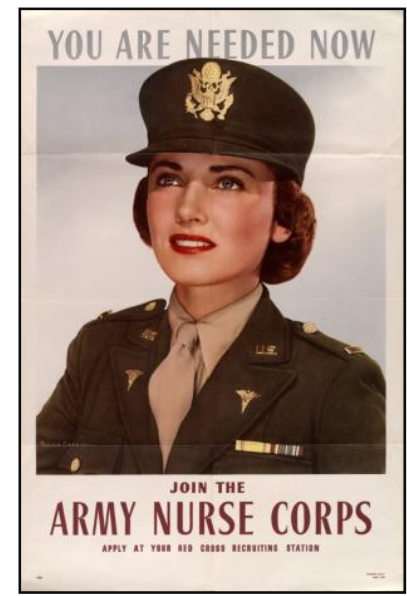

Plakat 3 


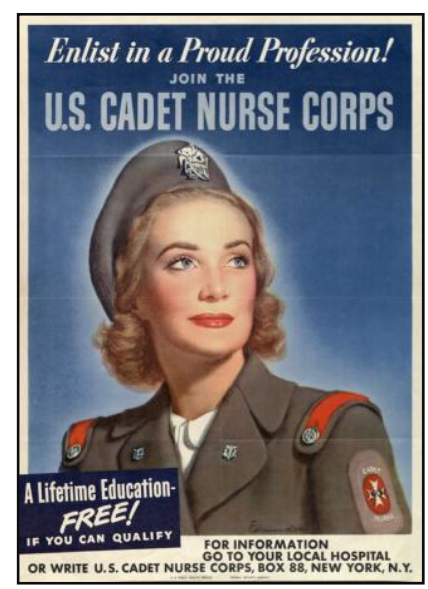

Plakat 2

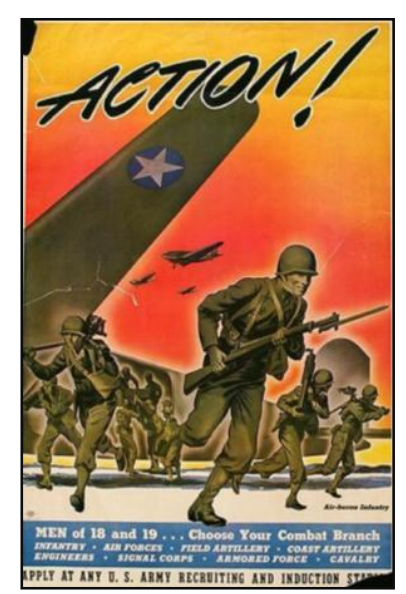

Plakat 8

zawsze ubrana w mundur służb, do których wstąpienia ma zachęcać. Mundury te zobrazowane są zwykle z najdrobniejszymi szczegółami (np. plakaty 1-3) i nawet w sytuacji bojowej (plakat 8) są schludne i czyste.

Przedstawione umundurowanie jest zwykle kompletne - uzupełnione nakryciem głowy i bronią. Rzadko na plakacie widnieją inne rekwizyty uzupełniające przekaz. Jeśli nawet przedstawiony jest dodatkowo jakiś obiekt, to fragmentarycznie, jedynie jako element uzupełniający, np. fragment samolotu - plakat 1, część koła sterowego - plakat 5, fragment działa okrętowego - plakat 9.

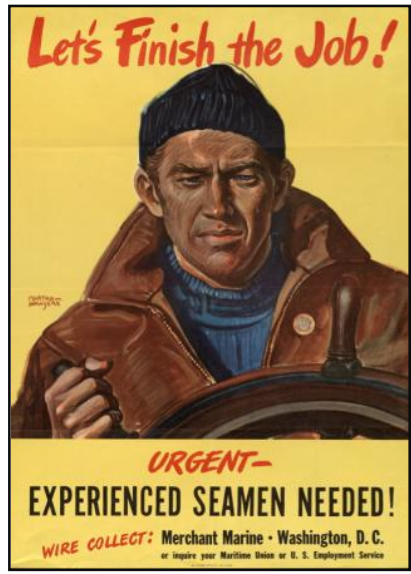

Plakat 5

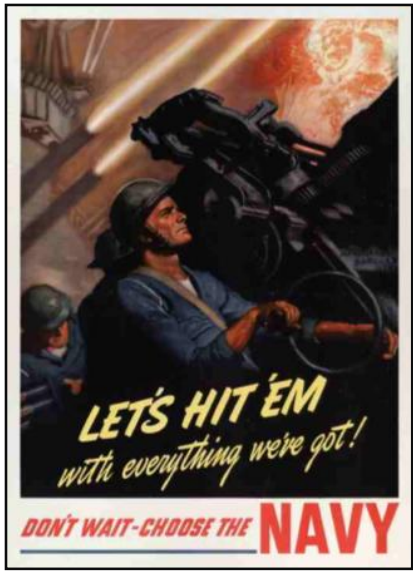

Plakat 9 
Analiza dyskursywna amerykańskich plakatów rekrutacyjnych...

Wytłumaczenie częstszego przedstawiania na plakatach propagandowych jednostek proponuje Tomasz Ferenc:

\begin{abstract}
Istota ludzka wpleciona $\mathrm{w}$ tryby militarnej machiny staje się głównym nośnikiem informacji, perswazji, przestrogi. Z plakatów spoglądają na nas realistycznie namalowani ludzie [...]. Oczywiście celem takiego przedstawienia jest umożliwienie jak najłatwiejszej identyfikacji odbiorcy z ukazywaną postacią. To nie jest jakaś abstrakcyjna istota, ale jeden $\mathrm{z}$ nas. Jeden, bo łatwiej się identyfikować z konkretną osobą niż z grupą ludzi lub tłumem (Ferenc 2009: 249).
\end{abstract}

W większości zanalizowanych przypadków postaci przestawiane są w tak zwanym ujęciu trzy czwarte ${ }^{9}$ - nadaje to twarzy trójwymiarowości i sprawia, że przedstawiana postać - nawet, jak w większości przypadków, rysunkowa - odbierana jest jako realna i prawdziwa. Bohaterowie plakatów nie spoglądają na swojego widza, lecz wzrok mają skierowany lekko w bok i w górę (powyżej linii oczu) - np. plakat 1 . Brak kontaktu wzrokowego z odbiorcą i spojrzenie utkwione gdzieś $\mathrm{w}$ dali pozwala odczytywać przekaz na poziomie publicznym, służbowym, oficjalnym. Postać patrząca $w$ dal, przed siebie, odczytywana jest jako pochłonięta myślami o rzeczach wzniosłych i ważnych ${ }^{10}$. Spoglądanie na odbiorcę czyni przedstawianą postać bardziej prywatna, wprowadza również bardziej osobowy i indywidualny kontakt z widzem. Zrezygnowanie $\mathrm{z}$ takiego indywidualnego sposobu przedstawiania bohaterów sugeruje oficjalny charakter przekazu oraz postrzeganie tych postaci przede wszystkim przez pryzmat mundurów, jakie noszą. Innymi słowy jako reprezentantów wojsk, do których wstępowania zachęcają. Oficjalność ta wbudowana jest również w sposób przedstawienia postaci - dominuja plany pełne, które konotują dystans i również nadają osobom przestawionym charakter publiczny oraz półzbliżenia, które kierują uwagę widza na noszone przez bohaterów mundury, co sugeruje "zawodowy" poziom odczytania przedstawionych postaci (Rose 2007). Jak wcześniej wspomniałam, plakat, mimo że $\mathrm{w}$ założeniu był medium nieskomplikowanym, musiał być jednak zauważany. Elementem, który miał realizować tę ważną funkcję wyrazisto-

${ }^{9}$ Jest to taki sposób przedstawienia twarzy, kiedy jest ona zwrócona lekko w bok, ale widoczne są oboje oczu.

${ }^{10}$ Najsłynniejsza, wręcz ikoniczna, egzemplifikacją takiego przedstawiania postaci jest portret Ernesta „Che" Guevary autorstwa Alberta Kordy. 
ści i przyciągania uwagi był często kolor. Kolorem najbardziej lubianym przez twórców amerykańskich plakatów rekrutacyjnych okresu II wojny światowej była barwa niebieska. Niebieskie jest przede wszystkim tło dla przedstawianych postaci, niebieskie czy też niebieskawe są mundury tychże osób, w odcieniach niebieskiego często zaprojektowane jest również liternictwo. Niebieski występuje zwykle w bardzo różnorodnych odcieniach - o zróżnicowanym walorze i nasyceniu: od delikatnego, ledwie widocznego szaroniebieskiego, do nasyconego granatu (np. plakaty 3, 6, 7).

Drugim ważnym kolorem $\mathrm{w}$ przekazie plakatów rekrutacyjnych jest czerwień. $\mathrm{W}$ porównaniu $\mathrm{z}$ barwą niebieską, która zwykle pojawia się jako wypełniająca przekaz, czerwień stosowana jest dwojako. $Z$ jednej strony może ona dominować (w znaczeniu: przeważać nad barwą niebieską) i zajmować znaczną część przestrzeni plakatu (plakat 8). Z drugiej strony czerwień służy do przedstawiania i akcentowania detali - kolorem czerwonym często wyróżnione jest liternictwo lub też podkreślane są niewielkie, lecz ważne z punktu widzenia przekazu detale - np. elementy munduru czy mocno czerwona szminka na ustach pielęgniarek i żołnierek (plakaty 2 i 3 ).

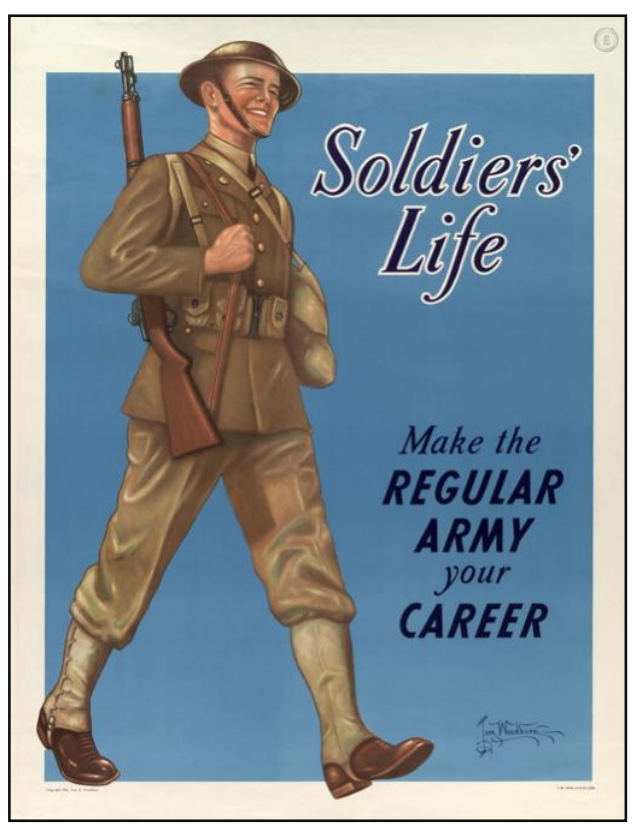

Plakat 6

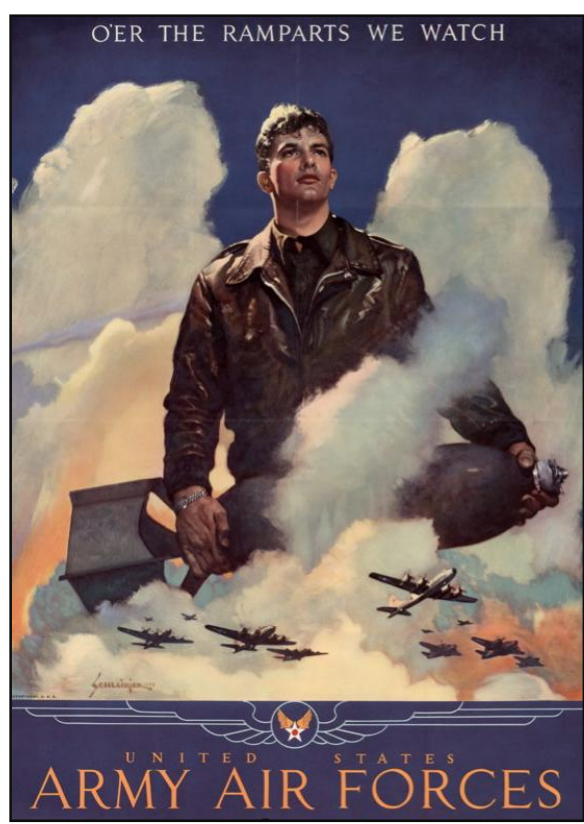

Plakat 7 
Rzadziej od koloru niebieskiego „partnerem” czerwieni jest bliski jej, wedle typologii Bergströma, kolor żółty. Tandem ten widnieje np. na plakacie zachęcającym do wstępowania do marynarki wojennej (5), na żółtym tle (sporadyczny przypadek złamania reguły tła niebieskiego) zastosowano czerwone liternictwo. Jednak w tym przypadku zamierzony kontrast „uspokajają" barwy: niebieska (golf i oczy marynarza) oraz brązowa (jego twarz, kurtka i koło sterowe).

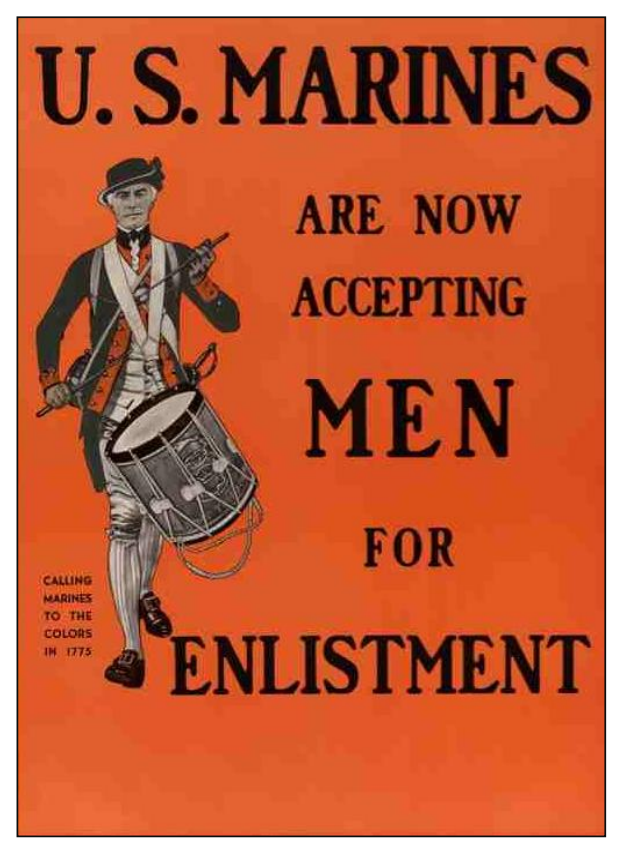

Plakat 4

Interesujące jest, że w zebranym materiale badawczym epizodycznie jedynie pojawiają się przypadki wykorzystania najbardziej kontrastowych - krzyczacych wedle terminologii Bergströma, zestawień kolorystycznych, o które upominali się wspomniani wcześniej teoretycy plakatu. Przykładem takiego postulowanego, a przy tym niezwykle rzadkiego, sposobu zastosowania kolorów jest plakat utrzymany w wyrazistej, ale i prostej pomarańczowo-czarnej kolorystyce: czarna sylwetka dobosza przedstawiona na pomarańczowym tle (plakat 4).

Jednak w większości zanalizowanych przypadków użyty został zbiór dwóch, trzech bliskich sobie, szepczacych barw (np. kolor zielony, niebieski i szary) - plakaty 1, 3, 6 albo też dominują dwie barwy odróż- 
niające się, lecz rozmawiajace, czyli nadal harmonijnie ze sobą współdziałające, np. kolory niebieski i czerwony (plakaty 2 i 8). Dla uzasadnienia takiego wyboru palety barw można przyjąć argumentację Rose, która zauważa, że użycie kolorów zbliżonych do tych występujących w naturze i łączenie ich również z barwami, z którymi współwystępują w rzeczywistości zwiększa realistyczność, a co za tym idzie, wiarygodność przekazu (Rose 2007: 42). O większej perswazyjności przekazu odczytywanego jako odzwierciedlający rzeczywistość pisze np. Anna Chudzik (2006: 120):

w potocznym odbiorze obrazowe, wizualne przedstawienie wykazuje dla odbiorcy stosunkowo duży stopień podobieństwa do denotowanego elementu rzeczywistości. Obraz przedmiotu jest też łatwo przyswajalny, nie wymaga tyle wysiłku i czasu, co odebranie informacji zakodowanej symbolicznie [...] i dlatego jest chętnie wykorzystywanym sposobem kodowania informacji w przekazach o funkcji reklamowej.

Interesujące mnie szczególnie kolory, niezależnie od niesionej treści symbolicznej, zawsze funkcjonują na poziomie denotacyjnym, na którym zatrzymuje się oko widza, niewprawionego w odczytywaniu innych, uwarunkowanych kulturowo, poziomów przekazu. Przykładowo kolor niebieski wypełniający często tło plakatu, wpisuje się w oparte na codziennych doświadczeniach rozumienie przekazu wizualnego - niebieskie jest np. niebo. Powszechnie wiadomo, że pochmurne niebo - często pojawiające się $\mathrm{w}$ tle zarówno na fotografiach, jak i malarskich scenkach rodzajowych czy portretach - jest realistycznym, prawdziwym dopełnieniem przedstawianej postaci, a nie nośnikiem abstrakcyjnych wartości, takich jak ład czy sprawiedliwość.

\section{Analiza kontekstualna plakatu rekrutacyjnego}

\section{Niebieski}

By móc odczytać konotacje wypełniającego przekaz kulturowy koloru niebieskiego, można odwołać się do ustaleń dotyczących funkcjonowania tejże barwy w języku. Uczeni zajmujący się semantyką barw są zgodni, że najstarsze symboliczne znaczenie tej barwy związane 
Analiza dyskursywna amerykańskich plakatów rekrutacyjnych...

było z kontekstem religijnym - niebieski był kolorem przede wszystkim bóstw oraz sfery sacrum. Ciekawie pisze o tym powiązaniu Ryszard Tokarski:

Niebieski (błękitny) jest semantycznie motywowany przez niebo i konotacje tych barw rozwijają się w dużym stopniu paralelnie do konotacji nazwy je motywującej. Niewątpliwie konotacje nieba rozwijały się w dużej zależności od religii chrześcijańskiej, w której, [...] firmament niebieski zespolił się znaczeniowo z miejscem będącym siedzibą Boga, aniołów i świętych, oraz miejscem szczęśliwego pobytu zbawionych, błogosławionych dusz ludzkich (Tokarski 1995: 138).

Autor odnosi się również do współczesnego kulturowego funkcjonowania barwy niebieskiej, które podsumowuje następująco: „właściwe niebu konotacje »doskonałości «, »szczęścia« przenoszone bywają na barwę niebieską (błękitną)" (Tokarski 1995: 139; Popek 2008). Można zatem stwierdzić, że współczesne kulturowe odczytania barwy niebieskiej występujące w języku (zarówno werbalnym, jak i wizualnym) opierają się na wskazanym fundamencie religijnym (w naszym kręgu kulturowym przede wszystkim chrześcijańskim). Dlatego współcześnie wskazywane odniesienia barwy niebieskiej, mniej lub bardziej bezpośrednio, odwołują się do paradygmatu chrześcijańskiego i opierają się na takich pojęciach, jak sprawiedliwość, dyscyplina, porządek ${ }^{11}$.

W zebranym materiale znajdują się ilustracje literalnego nawiązania do pierwotnego - sakralnego - znaczenia tejże barwy. Na przykład na plakacie zachęcającym do wstępowania do lotnictwa (7) przekaz zbudowany jest wokół ponadnaturalnej postaci lotnika, który jest nie tyle umieszczony na tle nieba, co raczej stoi w chmurach, otoczony maleńkimi - $\mathrm{w}$ porównaniu $\mathrm{z}$ nim - samolotami. Lotnik dzierży w dłoniach ogromny pocisk i (zgodnie z przyjętą konwencją) spogląda w dal. Wielkości i męskości dodaje mu też żabia perspektywa, z której jest przedstawiony. Taki, niosący boskie konotacje, sposób przedstawienia postaci dopełniany jest otaczającymi sylwetkę lotnika chmurami, które układają się w ogromne białe (anielskie?) skrzydła.

${ }^{11}$ Do podobnych wniosków, na polu językoznawstwa, dochodzi Alicja Nowakowska, pisząc o występowaniu „barwy niebieskiej” w języku polskim: „We współczesnej polszczyźnie przymiotnik błękitny wnosi zdecydowanie pozytywne konotacje ładu, porządku, rozsądku" (Nowakowska 2008: 250). 
Jednak w większości plakatów, kolor niebieski nie ma tak bezpośrednich odniesień do boskich konotacji tej barwy. Kolor ten stanowi zwykle naturalne tło portretowanych osób. Jak już wspomniałam, takie neutralne w założeniu zastosowanie barwy daje możliwość wykorzystania jej kulturowego znaczenia i kształtowania odbioru przekazu bez narażania się na zarzut manipulowania nim.

Gdy mamy do dyspozycji szerokie spektrum możliwych konotacyjnych odczytań barwy niebieskiej, pomocne przy wyborze dominującego semantycznego odczytania mogą być formalne rozwiązania kompozycyjne wskazane we wcześniejszych akapitach tego rozdziału. $\mathrm{Z}$ analiz tych można wysnuć następujące wnioski: przekaz niesiony za pomocą plakatów powinien odnosić się do wartości będących wyposażeniem kulturowym odbiorcy - poster winien być odczytywany jednoznacznie przez każdego, kto na niego spoglądał - z jednej strony jak najszerzej społecznie podzielanych (uniwersalnych), z drugiej bez trudu odczytywanych bezpośrednio przez jednostkę. Podkreślana na poziomie obrazu ideowość i górnolotność (spojrzenie utkwione ponad linią horyzontu) przywołują na myśl wartości w dominującym amerykańskim dyskursie najważniejsze i nienegocjowalne, oraz, co równie ważne dla jednoznaczności odczytania, w ten sam sposób obrazowane, jak patriotyzm, poświęcenie się dla ojczyzny.

\section{Czerwony}

Opisywana powyżej barwa niebieska jest ważnym elementem większości analizowanych plakatów, lecz poza incydentalnymi próbami zbudowania całego przekazu propagandowego wokół tego koloru, niebieski zwykle współwystępuje z odcieniami barwy czerwonej, czasem jeszcze z dodatkiem koloru żółtego (plakaty 5 i 8).

Czerwień z pewnością jest jedną z najważniejszych kulturowo barw - to pierwszy kolor chromatyczny - po bieli i czerni - który pojawia się leksykalnie $\mathrm{w}$ językach różnych kultur $\mathrm{z}$ całego świata. Czerwień jest również kolorem bardzo wysoko cenionym przez badaczy - wedle Ryszarda Tokarskiego czerwień jest to „kolor najdoskonalszy” - „czerń daje początek innym barwom, ale barwą najdoskonalszą, utożsamianą ze złotem i ogniem, jest czerwień, symbol narodzin i wielkiego czynu" (Tokarski 1995: 87). Czerwień, podobnie jak opisywany wcześniej kolor niebieski, miała konotacje boskie: 
Analiza dyskursywna amerykańskich plakatów rekrutacyjnych...

od najwcześniejszych czasów czerwień była w wielu kulturach znakiem tego, co niebiańskie. [...] Przed V w. p.n.e. greckie stele nagrobne miały pomalowane na czerwono tła, chociaż te tła potem stawaty się niebieskie [podkreślenie moje - K. B.]. $\mathrm{Na}$ czerwono malowano też wnętrza niektórych świątyń, na przykład sanktuarium Afai na Eginie (Gage 2008: 26).

Później czerwień, utożsamiana z purpura, była kolorem symbolizującym władzę i (obok barwy złotej) bogactwo:

czerwień i różnorodne jej odcienie uchodziły za barwy atrakcyjne, nobilitujące, przynależne władcom i usytuowanym wysoko w hierarchii społecznej (Tokarski 1995: 96) $)^{12}$.

Współcześnie symbolika czerwieni nie opiera się już na sferze sacrum, wręcz przeciwnie - jest barwą kulturowo ściśle związaną z dwoma aspektami ludzkiego życia: krwią (symbolicznie reprezentującą ważne elementy ludzkiego życia - seksualność, narodziny, śmierć) i ogniem (związanym z odnowa, oczyszczaniem, walka, niszczeniem).

$\mathrm{Na}$ analizowanych plakatach czerwień również jest wykorzystywana $\mathrm{w}$ tych dwóch kontekstach. Wedle jednej strategii czerwień denotacyjnie przedstawia ogień (lub wschód słońca, o którym za chwilę), a na poziomie konotacji nawiązuje do walki i do przyszłego zwycięstwa.

Użycie czerwieni przy podkreślaniu detali (liternictwo i elementy umundurowania) może realizować zadanie „ożywienia” przekazu. W literaturze opisującej oddziaływanie kolorów na fizjologię już w połowie dwudziestego wieku dość powszechnie wskazywane były pobudzające właściwości barwy czerwonej: „W znaczeniu psychofizjologicznym barwa czerwona podnieca i przyspiesza tętno, zaś niebieska tłumi i zmniejsza tętno" (Zeugner 1965: 124; Popek 2008).

Chciałabym skoncentrować się na zastosowaniu czerwieni, skromnym z uwagi na skalę, ale moim zdaniem perswazyjnie ważnym - czerwonej szminki na ustach prezentowanych kobiet (plakaty 1-3). Przedstawiane panie - zarówno zachęcające do wstępowania do służb pomocniczych, jak i do regularnej armii ${ }^{13}$ - są nie tylko młode i ładne, ale i atrakcyjne seksualnie o starannym i wyrazistym makijażu, z mocno podkreślonymi ustami.

${ }^{12} \mathrm{~W}$ polskim kontekście politycznym kolor czerwony ma jeszcze jedno ważne odczytanie kulturowe. Barwa ta ma silne nacechowanie negatywne, będące konsekwencją poprzedniego ustroju politycznego i symbolicznego powiązania czerwieni z komunizmem czy socjalizmem (Nowakowska 2008).

${ }^{13}$ Od II wojny światowej kobiety mogły wstępować do armii amerykańskiej, a nie tylko do służb pomocniczych (Jarecka 2009). 
Warto zauważyć, że atrakcyjność fizyczna lub jej brak same w sobie są znakami (w typologii Peirce'a indeksami) kulturowymi, które stanowią ważne elementy gramatyki języka wizualnego - postulowane przez starożytnych myślicieli powiązanie piękna z dobrem, prawdą uczciwością na trwałe przeniknęło do kultury nowożytnej. Na współczesnym myśleniu o człowieku zostawiły również ślad przekonania, że choroby, kalectwo, deformacje i odmienności są karą za grzechy i sprawą przez daną jednostkę zawinioną:

W efekcie piękno i brzydota dostarczały znaku (przedstawienia) dla tego, co bezobrazowe, uruchamiając oparte na transgresji działanie symboliczne i metaforyczne. Jednocześnie poręczność i „podręczność" tych kategorii, skutkujące w powtarzającym się wiązaniu ich z tymi samymi wartościami, prowadziły do ich alegoryzacji (Szczęsna 2007: 267).

Uroda przedstawianych kobiet jest dowodem ich wiarygodności, a ich czerwone usta zwiększają perswazyjność przekazu dodatkowym, erotycznym wydźwiękiem ${ }^{14}$.

Połączenie barw czerwonej z żółtą może przydawać przekazowi dynamiczności i budzić denotacyjne skojarzenia z ogniem i z walką (zwycięską?) na poziomie konotacji (plakaty 8 i 9). Jest to jedno z najpowszechniejszych kulturowych odczytań czerwieni. Uważam jednak, że szczególnie w przypadku plakatu 8 można poszukać jeszcze innego możliwego odczytania połączenia czerwieni z żółcią. To drugie wyjaśnienie symboliki analizowanych barw zbliża je semantycznie do koloru pomarańczowego i jest nawiązaniem do kolorów wschodzącego słońca - które z kolei wzbudza konotacje związane z nadzieją i lepszym jutrem. Tokarski również widzi semantyczne podobieństwo między barwami żółtą i czerwoną a pomarańczową:

Pomarańczowy kumuluje bowiem niemal wyłącznie konotacje "ciepła”, w mniejszym może stopniu "blasku” oraz pochodne od nich, np. "radości”, które tworzą konotacyjne jądro oraz barwy żółtej i czerwieni. Nic więc dziwnego, że stereotypowa łączliwość tej nazwy barwy oraz nazw wariantów kolorystycznych jej przyporządkowanych dotyczy przede wszystkim słońca (rzadziej księżyca) i ognia (Tokarski 1995: 195).

${ }^{14}$ Możliwe jest również, o czym wspomina Urszula Jarecka (2009), że celem umieszczania pięknych żołnierek i pielęgniarek na plakatach wojennych, w tym tych rekrutacyjnych, był zabieg estetyzacji wojny i związanej z nią śmierci. 
O czerwieni, jako kolorze słońca pisze też wspomniany już Gage, opisując kulturowe funkcjonowanie koloru czerwonego w starożytności, podkreśla, że wówczas

czerwień uważano na szeroką skalę za kolor słońca; w niektórych rytach greckich czerwień używana była wymiennie z bielą w kontekście solarnym: poświęcona Heliosowi mozaika, zabytek z końca III w. n.e. w muzeum w Sparcie, ukazuje boga z czerwonawym nimbem, który wysyła czerwonawożółte, czerwone i białe promienie (Gage 2008: 26).

\section{Brak koloru}

Wspomniałam już, że strategie wyboru kolorów użytych w przekazie plakatowym determinowane były potrzebą realizmu - przez swą naturalność zwiększającego siłę oddziaływania perswazyjnego przekazu. Działo się tak przede wszystkim w przypadku plakatów rekrutacyjnych stworzonych techniką rysunku czy grafiki. Poniżej chciałabym przedstawić dążenie do realizmu oparte na zupełnie innym założeniu, wynikającym z ówczesnego odczytywania fotografii czarno-białych i kolorowych.

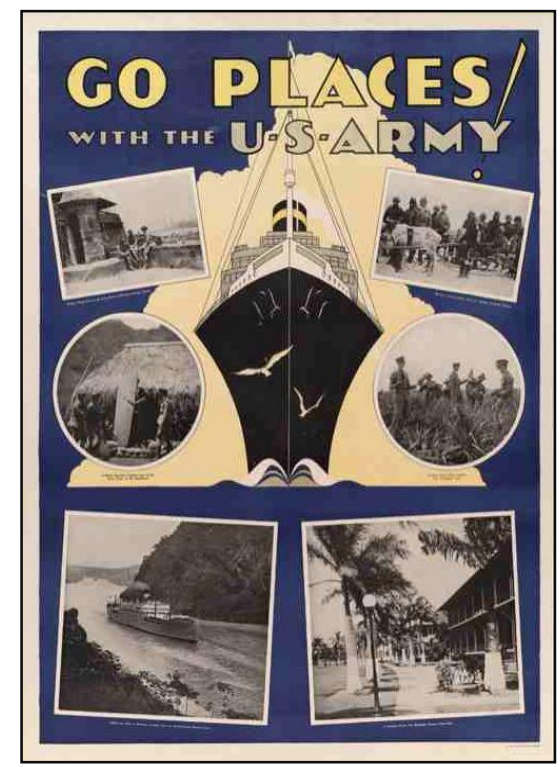

Plakat 10 


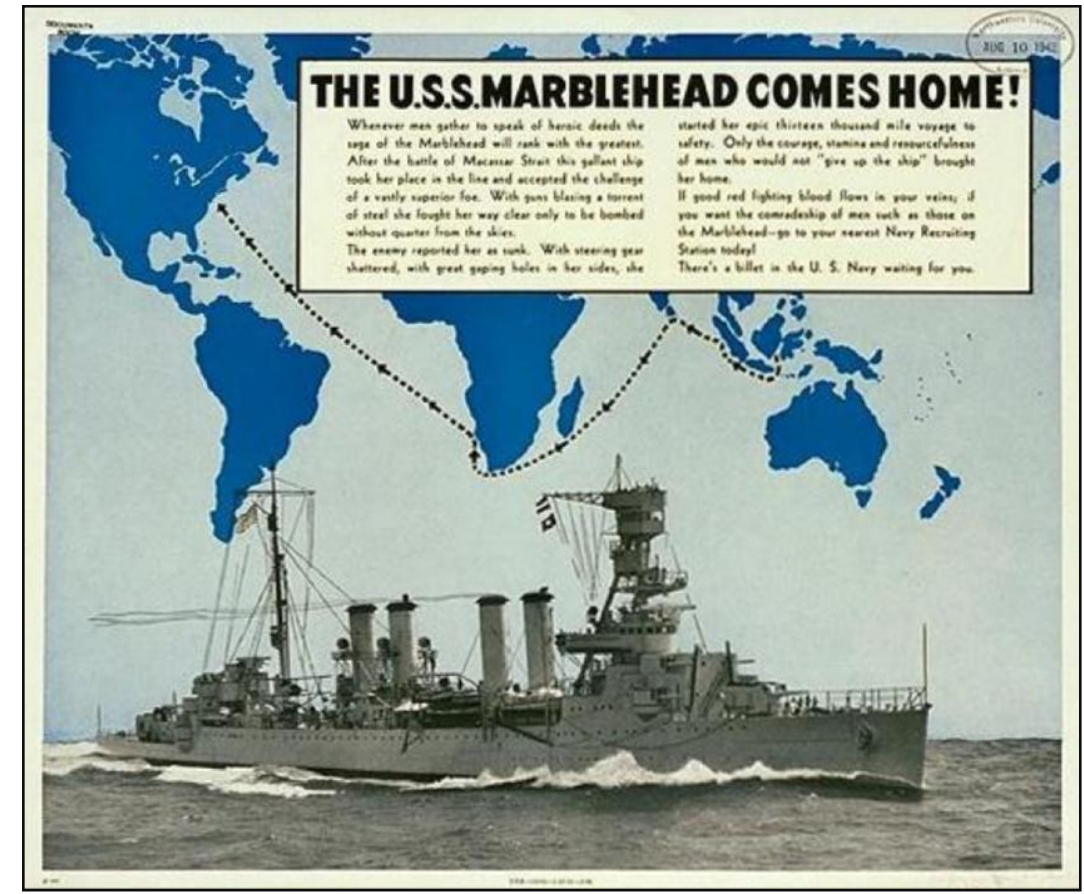

Plakat 12

Wśród plakatów rekrutacyjnych znajduje się grupa posterów, które utrzymane są $\mathrm{w}$ tonacji czarno-białej, czasem $\mathrm{z}$ dodatkiem jednej tylko barwy „kolorowej” - zwykle niebieskiej (plakaty 10 i 12). Pozbawione kolorów są plakaty, na których przekaz wizualny determinuje zastosowana tam czarno-biała fotografia. Te plakaty najczęściej są mocno rozbudowane w warstwie językowej - w odróżnieniu od plakatów „kolorowych", zazwyczaj zawierają kilka kolumn tekstu.

Konsekwentne wykorzystywanie $\mathrm{w}$ plakatach fotografii czarno-białych związane było z położeniem akcentu na ich prawdziwość i postulowanym odbiorem na serio. Do lat siedemdziesiątych ubiegłego stulecia używanie koloru w fotografii było sprawą problematyczną, szczególnie jeśli przekaz miał znaczyć więcej niż „pospolita” fotografia komercyjna:

Czerń i biel konotowały «poważną» fotografię artystyczną: były w naturalny sposób bardziej abstrakcyjne niż kolor i nadawały się do tworzenia symboli [...]. Na wystawie Rodzina człowiecza, która objechała świat w latach 1955-1959 i potwierdziła artystyczny potencjał fotografii prasowej, znalazła się tylko jedna fotografia barwna wybuch bomby wodorowej (Hoy 2006: 314). 
Dlatego dla nadania fotografii charakteru poważnej, obiektywnej, nawet społecznie zaangażowanej, unikano używania koloru.

Opisywana, utrzymywana $\mathrm{w}$ tonacji czarno-białej, kompozycja plakatów wpisuje się w przedstawiony przez Schirato i Webb wizualny sposób realizacji foucaultowskich reżimów prawdy. Badacze ci, pisząc o sposobach wizualnego obrazowania rzeczywistości za pomocą dyskursów dominujących, posługują się terminem reżimy wizualne (Schirato, Webb 2007: 131 i n.). Zauważają, że elementem czyniącym przekaz obiektywnym (naukowym) jest użycie fotografii. Jest to jednak ujęcie podtrzymujące dziewiętnastowieczne, pozytywistyczne pojmowanie fotografii jako przeźroczystego medium, którego zadaniem jest dokumentowanie i utrwalanie fragmentów rzeczywistości. Takie cechy dziewiętnastowiecznego pojmowania fotografii, jak: „wiara w wierność prezentacji świata, rejestracja prowadząca do uchwycenia prawdy [...] dominacja techniki i estetyki naturalistycznej" (Sztandara 2004: 29), nadal w myśleniu potocznym wyznaczają sposoby widzenia fotografii, szczególnie tej umieszczonej $\mathrm{w}$ dyskursie naukowym - w podręcznikach akademickich, encyklopediach, monografiach naukowych.

Użycie dokumentalnych, czarno-białych fotografii ma wydźwięk perswazyjny (plakaty 10 i 12). Samo realistyczne przedstawienie ogromnych, wzbudzających strach i podziw, maszyn wojennych - samolotów bojowych czy okrętów wojennych - ma nieść przekaz: "to są dowody potęgi wojskowej Stanów Zjednoczonych”, ale też "możesz być częścią tej potęgi". Fotografie przedstawiają również miejsca, do których można np. dopłynąć na statku marynarki wojennej. Tego rodzaju fotografie są niepodważalne, a ich przesłanie proste: "takie miejsca naprawdę istnieja, zabierzemy cię tam, gdy wstąpisz w nasze szeregi". Postulowana prawdziwość przekazu wymusiła użycie fotografii czarno-białej - wprowadzającej konwencję dokumentalną. Wyjątkiem, łamiącym zasadę realistycznego, czarno-białego dokumentu, jest plakat, do stworzenia którego wykorzystano kolorową fotografię kobiety zachęcającej do wstępowania do korpusu pielęgniarskiego (plakat 3). Ten projekt wpisuje się w inny schemat kompozycyjny, niż przykłady opisane powyżej. Kolorowe zdjęcie atrakcyjnej kobiety ma nęcić, obiecywać, a nie argumentować i udowadniać - stąd też kolor, który był nieodzownym elementem fotografii reklamowej.

W analizowanych przypadkach obiektywność przekazu budowana za pomocą fotografii przejawia się na przykład porównaniem postur młodych mężczyzn przed (powykrzywiane, wychudzone postaci) 


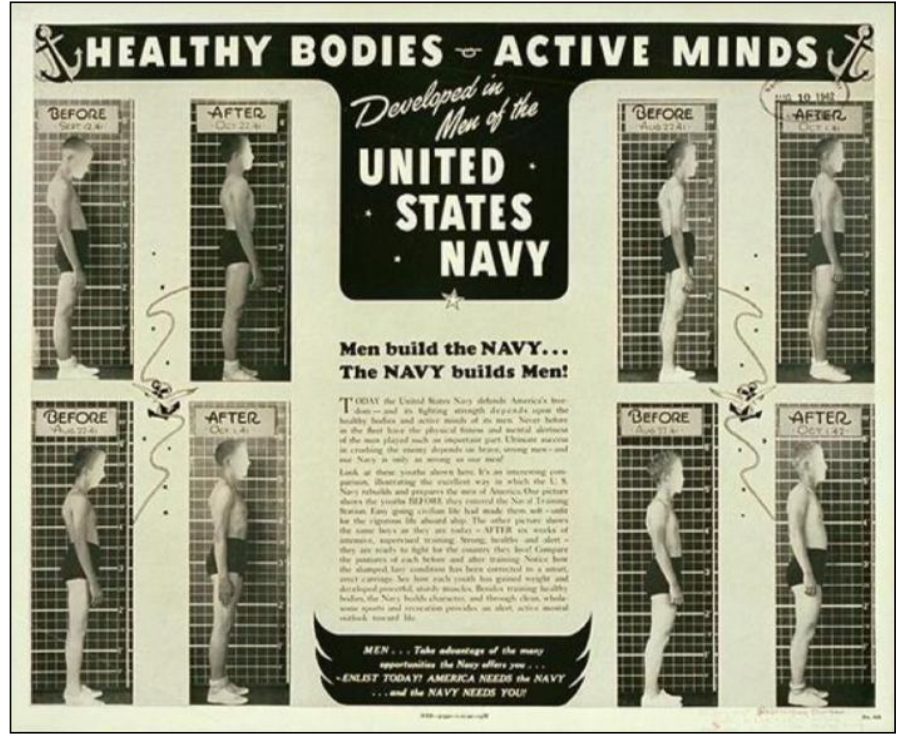

Plakat 11

i po (sylwetki wyprostowane i widocznie bardziej umięśnione) wstąpieniu do marynarki wojennej (plakat 11). Prezentowane osoby mają rozmazane twarze, ale nad każdą fotografią znajduje się data wskazująca, kiedy dane zdjęcie zostało wykonane. Pozwala to na porównanie wyników przedstawionych badań. Innym przykładem naukowego prezentowania informacji jest plakat, na którym w tle (błękitnym) sfotografowanego (czarno-białe zdjęcie) okrętu, przedstawiona jest mapa świata utrzymana w niebieskiej kolorystyce. Na mapie tej, z kolei, za pomocą linii i strzałek zaznaczona jest droga powrotna wojennego okrętu z Archipelagu Malajskiego do Stanów Zjednoczonych - mapy, wykresy i strzałki, to również elementy sugerujące naukowość i obiektywność.

\section{Zakończenie}

W powyższym rozdziale przedstawiłam zarys możliwości, jakie daje analiza dyskursu oparta na materiale wizualnym. Jest to metoda pracy badawczej rozwijająca się i dlatego niepozbawiona wad. Podjęcie się ana- 
lizy wizualnego dyskursu wymaga od badacza samodyscypliny oraz krytycznego podejścia (zarówno do analizowanej materii, jak i do siebie samego - uwikłanego przecież kulturowo i ideologicznie człowieka) i wiedzy daleko wykraczającej poza jego macierzystą dyscyplinę naukową. Z drugiej strony, niewątpliwym plusem tego podejścia jest interdyscyplinarność - możliwość korzystania z osiagnięć i metod wypracowanych przez różne, czasem odległe własnej dyscyplinie, dziedziny naukowe. DA daje również możliwość dotarcia do poziomu światów społecznych konstruowanych (dzięki koncentracji na realnie istniejących danych) przez jednostki, a nie badaczy. $Z$ powodu bogactwa tematu nie mogłam poruszyć wszystkich wątków związanych z analizą dyskursu przedstawionych plakatów rekrutacyjnych. Poza moimi rozważaniami pozostała np. relacja między przekazem wizualnym a werbalnym zamieszczonym na plakacie (Piekot 2006).

Jednym z zadań, jakie postawiłam przed sobą pisząc ten rozdział, było pokazanie, w jaki sposób kolor, szczególnie ten zastosowany w celu przedstawienia realistycznego, może być narzędziem perswazji. Ufamy przekazowi realistycznemu (o którego prawdzie $\mathrm{m}$. in. świadczy zastosowana kolorystyka), na sposób dziewiętnastowieczny wierzymy, że przedstawia świat i rzeczy takimi, jakie one są naprawdę ${ }^{15}$ (Berger 2009; Rose 2007). Dlatego, mimo że materia ta ciaggle umyka spojrzeniu naukowemu, uważam, że ważne jest, by próbować ogarniać kulturową przestrzeń koloru (jak i całej ikonosfery), bo jest to refleksja ubogacająca wiedzę na temat życia codziennego, które jest przecież na wielu różnych płaszczyznach zanurzone w barwach (i w obrazach).

\section{Bibliografia}

Berger, J., (2009), Sposoby widzenia. Warszawa: Aletheia.

Bartmiński, J., (1990), Punkt widzenia, perspektywa, językowy obraz świata, [w:] J. Bartmiński (red.), Jezzkowy obraz świata. Lublin: Wydawnictwo UMCS.

Bergström, B., (2009), Komunikacja wizualna. Warszawa: Wydawnictwo Naukowe PWN.

15 Świadectwem epoki - ówczesnego myślenia o fotografii - może być szyld reklamowy pierwszego na świecie studia portretu, założonego w roku 1840 w Nowym Yorku, które brzmiało: „miniatury światłem malowane... z wiernością tak doskonałą jak sama natura" (Hoy 2006: 64). 
Bernstein, D., (2005), Billboard! Reklama otwartej przestrzeni. Warszawa: Wydawnictwo Naukowe PWN.

Chlewiński, Z., (1999), Dynamiczna organizacja pojęć. Warszawa: Wydawnictwo Naukowe PWN.

Chudzik, A., (2006), Typ ikoniczności w szyldach, [w:] E. Tabakowska (red.), Ikoniczność znaku. Kraków: Universitas.

D' Alleva, A., (2006), Jak studiować historię sztuki. Kraków: Universitas.

Fairclough, N., (1995), Critical Discourse Analysis: the Critical Study of Language. London: Longman.

Ferenc, T., (2009), Bohater, wróg, zdrajca - amerykańskie i niemieckie plakaty z okresu II wojny światowej, [w:] M. Lisiecki (red.), Sztuki wizualne jako nośniki ideologii. Toruń: Wydawnictwo Adam Marszałek.

Foucault, M., (1993), Nadzorować i karać: narodziny więzienia. Warszawa: Altheia-Spacja.

Gage, J., (2008), Kolor i kultura. Teorie i znaczenie koloru od antyku do abstrakcji. Kraków: Universitas.

Hoy, A. H., (2006), Wielka księga fotografii. Warszawa: Wydawnictwo G+J RBA.

Jarecka, U., (2008), Propaganda wizualna stusznej wojny. Warszawa: Wydawnictwo IFiS PAN.

Jarecka, U., (2009), Nikczemny wojownik na stusznej wojnie. Wybrane aspekty obrazu wojny $w$ mediach wizualnych. Warszawa: Wydawnictwo Trio.

Król, E. C., (1999), Propaganda i indoktrynacja narodowego socjalizmu w Niemczech 1919-1945. Warszawa: Wydawnictwo IS PAN, Oficyna Wydawnicza RYTM.

Kubuj, D., (2006), Outdoor. Reklama zewnętrzna w kontekście historii i wspótczesności. Warszawa: Ströer Media.

Lewiński, P. H., (2008), Retoryka reklamy. Wrocław: Wydawnictwo Uniwersytetu Wrocławskiego.

Mascelli, J., (2008), Pięć tajników warsztatu filmowego. Warszawa: Wydawnictwo Wojciech Marzec.

Nowakowska, A., (2008), Semantyka barw w stużbie ideologii, [w:] I. Kamińska-Szmaj, T. Piekot, M. Poprawa, (red.), Ideologie w stowach i obrazach. Wrocław: Wydawnictwo Uniwersytetu Wrocławskiego.

Ossowski, S., (1958), U podstaw estetyki. Warszawa: PWN.

Piekot, T., (2006), Dyskurs polskich wiadomości prasowych. Kraków: Universitas.

Popek, S., (2008), Barwy i psychika. Percepcja, ekspresja, projekcja. Lublin: Wydawnictwo UMCS.

Potter, J., (1998), Discoursive Social Psychology: From Attitudes to Evaluative Practices, „European Review of Social Psychology", No 9: 233-266.

Potter, J., Edwards D., (1999), Social Representation and Discursive Psychology: From Cognition to Action, "Culture and Psychology", No 5: 447-458.

Potter, J., Wetherell, M., Gill, R., Edwards, D., (1990), Discourse: Noun, Verb or Social Practice? „Philosophical Psychology”, No 3: 205-217.

Rewers, E., (1995), Teoria dyskursu i ich znaczenie dla badań nad literatura, „Kultura i Społeczeństwo", nr 1.

Rose, G., (2007), Visual Methodologies. An Introduction to the Interpretation of Visual Materials. Los Angeles-London-New Delhi-Singapore: Sage.

Ross, P. E., (2004), Wszystkie barwy języka, „Świat Nauki”, nr 6: 26-27. 
Analiza dyskursywna amerykańskich plakatów rekrutacyjnych...

Schirato, T., Webb, J., (2007), Understanding the visual. Los Angeles-London-New DelhiSingapore: Sage.

Stafiej, A., (2002), Historia reklamy społecznie użytecznej, [w:] D. Maison, P. Wasilewski (red.), Propaganda dobrych serc czyli rzecz o reklamie społecznej. Warszawa: Agencja Wasilewski.

Sturken, M., Cartwright, L., (2001), Practises of looking. An introduction to visual culture. Oxford: Oxford University Press.

Szczęsna, E., (2007), Perswazyjność piękna, [w:] K. Wilkoszewska (red.), Wizje i re-wizje. Wielka księga estetyki w Polsce. Kraków: Universitas.

Sztandara, M., (2004), Słów kilka o fotografii. Propozycje badawcze i możliwe interpretacje, [w:] G. Pełczyńki, R. Vorbrich (red.), Antropologia wobec filmu i fotografii. Poznań: Biblioteka Telgte Wydawnictwo.

Tokarski, R., (1995), Semantyka barw we wspótczesnej polszczyźnie. Lublin: Wydawnictwo Uniwersytetu Marii Curie-Skłodowskiej.

Widdowson, H. G., (2004), Text, Context, Pretext. Critical Issues in Discourse Analysis. Oxford: Blackwell Publishing.

Witkowski, T., (2003), World War II poster campaings: preaching frugality to American Consumers. „Journal of Advertising", No 31 (1): 69-82, za: Kubuj, D., (2006), Outdoor. Reklama zewnętrzna w kontekście historii i wspótczesności. Warszawa: Ströer Media.

Wyrwas, K., Sujkowska-Sobisz, K., (2005), Mały stownik terminów teorii tekstu. Warszawa: Rytm.

Zausznica, A., (1959), Nauka o barwie. Warszawa: PWN.

Zeugner, G., (1965), Barwa i człowiek. Warszawa: Wydawnictwo Arkady.

\section{Informacje na temat wykorzystanych w pracy plakatów:}

\section{Plakat 1}

Agencja rządowa: United States. Marine Corps Women's Reserve, 1942

Tytuł: So proudly we serve: U.S. Marine Corp: Women's Reserve

Źródło: University of Minnesota Libraries, http://digital.lib.umn.edu/warposters/

\section{Plakat 2}

Agencja rządowa: United States. Public Health Service, 1943

Tytul: Enlist in a proud profession!: join the U.S. Cadet Nurse Corps: a lifetime education - free!

Źródło: Northwestern University Library, http://digital.library.northwestern.edu

\section{Plakat 3}

Agencja rządowa: United States. Public Health Service, 1944

Tytut: Be a cadet nurse: the girl with a future

Źródło: Northwestern University Library, http://digital.library.northwestern.edu

\section{Plakat 4}

Agencja rządowa: United States. Marine Corps, brak roku wydania,

Tytuł: U.S. Marines: are now accepting: men: for enlistment: calling marines to the colors in 1775

Źródło: University of Minnesota Libraries, http://digital.lib.umn.edu/warposters/ 


\section{Plakat 5}

Agencja rządowa: United States. Maritime Commission, 1944

Tytut: Let's finish the job!: urgent - experienced seamen needed

Źródło: Northwestern University Library, http://digital.library.northwestern.edu

\section{Plakat 6}

Agencja rządowa: United States. Army, 1941

Tytuł: Soldiers' life: make the: regular army: your: career

Źródło: University of Minnesota Libraries, http://digital.lib.umn.edu/warposters/

\section{Plakat 7}

Agencja rządowa: United States. Army Air Forces. / Brown \& Bigelow, 1945

Tytul: O'er the ramparts we watch

Źródło: Northwestern University Library, http://digital.library.northwestern.edu

\section{Plakat 8}

Agencja rządowa: United States. Army. Recruiting Publicity Bureau, 1942

Tytuł: Action!: men of 18 and 19, choose your combat branch

Źródło: Northwestern University Library, http://digital.library.northwestern.edu

\section{Plakat 9}

Agencja rządowa: United States. Navy, brak roku wydania,

Tytut: Let's hit 'em : with everything we've got!: don't wait - choose the navy

Źródło: University of Minnesota Libraries, http://digital.lib.umn.edu/warposters/

\section{Plakat 10}

Agencja rządowa: United States. Army, brak roku wydania,

Tytut: Go places!: with the: U.S. Army!

Źródło: University of Minnesota Libraries, http://digital.lib.umn.edu/warposters/

\section{Plakat 11}

Agencja rządowa: United States. Bureau of Naval Personnel, 1942

Tytur: Healthy bodies, active minds: developed in men of the United States Navy

Źródło: Northwestern University Library, http://digital.library.northwestern.edu

\section{Plakat 12}

Agencja rządowa: United States. Bureau of Naval Personnel, 1942

Tytuł: The U.S.S. Marblehead comes home!

Źródło: Northwestern University Library, http://digital.library.northwestern.edu 